\title{
Social Media as an Alternative to Peer Reviewed Journal Publications
}

\section{Prakash*}

Primary and Revision Joint Replacement Surgeon, Chennai, India

*Corresponding Author: L Prakash, Primary and Revision Joint Replacement

Surgeon, Chennai, India.
Received: January 07, 2021

Published: January 22, 2021

(C) All rights are reserved by $\mathbf{L}$ Prakash.

\section{Abstract}

Medical professionals are under great pressure to write academic articles and get them published in reputed journals. As publications contribute significantly to the career prospects, promotions, and academic growth, a paradoxical situation exists in medical publishing, where instead of the author being paid for his articles he is expected to pay the publisher to get published.

Social media has these days emerged as a reasonably attractive alternative to peer reviewed journals, and many medical professionals have taken to sharing their ideas across these platforms as an alternative to peer reviewed academic publications. The present article discusses the changing trend and the pros and cons of this approach.

Keywords: Social Media; Orthopaedics; Journal

\section{Publish or perish}

"Publish or perish" [1,2] that is the common saying in our field of orthopaedics and medicine, and is well accepted. Nevertheless in my 40 years career in orthopaedics I have published less than 18 papers in journals, though I have written more than 50 orthopaedic related books, conducted 126 hands on surgical workshops, given over 300 lectures and orations and conducted numerous online courses!

In addition to this, I can happily lay claim to at least 9 inventions/discoveries, either alone or in collaboration with other scientists, which are now being termed as game changers in orthopaedics! [3].

So if I don't take any interest in publishing, how do my ideas reach my peers, how do other surgeons and by proxy their patients benefit? How do my thoughts and creations, (purely level 5 evidence) percolate amongst my colleagues and peers? How does it get validated, accepted or rejected? Even if not for the patient's benefit, how does it assuage my ego that I have contributed something worthwhile to leave the footprints on sands of time?

The rat race to get published

This brings us to the first question! What are the aims of publications in journals? [4]. Medical publication is rather strange field where the rules are opposite of norms. I write fiction, crime novels, science fiction, thrillers, movie scripts etc., and every time I place my material with a publisher, I get paid for my contribution and creation! Exactly the opposite seems to be happening in the field of orthopaedic and medical publications! Doctors are forced to actually pay to get their articles published! Even the top most journals in orthopaedics like J.B.J.S, and Injury these days ask for a payment from the author to publish their research or observations! [5].

Surprisingly despite hefty charges to get published, both respected and predatory journals never seem to have any trouble in 
getting authors and papers [6]. Respected indexed journals with high citation factor, hardly publish 8 to 10 percent of their submissions, and many surgeons continue to submit and send money for article processing despite multiple rejections! [7].

This brings us to the second question. How do surgeons ensure that their paper is accepted in a peer reviewed indexed journal? Papers are published for three or four reasons [8].

- The research is original and contributes important valuable information, which would contribute to patient management and benefit.

- The paper is written in the correct format, following all the rules these journals make for their papers, including statistics, which to my mind appears as a deliberate obfuscation and making simple things complex.

- The paper is written by someone who is a well known "Big name", whose contributions will bring name and fame to the journal! [9]

To conform to the above requirements, it is the usual practice to cook up the statistics, change real data, eliminate the failures, concentrate on the success only, include a well known senior professor as the main author, or more simply, just sit at home, collect all papers published so far on your topic, and do a meta analysis! [10].

The trouble in this model is that less than $40 \%$ publications contribute anything signifiant, less than $15 \%$ papers are true or honest in their entirety, and most publications are not read by more than a handful of people, and once it is published, the surgeons purpose is solved. No wonder if indexed premier journals refuse a paper, it easily finds place in the next rung of predatory journals! [11].

\section{Why are surgeons impelled to publish?}

Coming back to the original question, "When I create something, I expect to be paid for my creation. If I am a philanthropist and a saint, I give my creation away for free! But why the hell should anyone with a sane mind actually pay to get himself published?

Eight important reasons come to my mind!

- I work in a university or academia, and my professional ladder can only be climbed on the rungs of publications! [12]
- I work in government sector or medical college, where I need to show $\mathrm{x}$ number of publications annually to maintain my status or improve my status professionally and personally! [13]

- My student/PG has done a thesis, and this has to be published. I get my name added free! Who has refused a freebie?

- I am being paid by a Pharma company to promote their drugs/ formulations. It does not matter if the drug is effective or a dud! But having been paid, I have to promote the sponsors.

- An implant or instrument manufacturer who wants to ensure continued sales of his products pays for my air tickets, or international travel, conference delegate fees, or sponsors other luxuries, and as a quid pro quid I have to publish papers to promote these [14].

- I am an inventor designer who has invented a new surgical procedure or a new design implant, and a combination of ego or commerce (ego in case of new technique and commerce in case of new implant), and this impels me to be desperate for a peer reviewed publication!

- "You scratch my back, I scratch yours" When I was a reviewer I accepted your paper, so you now better accept mine, as I need publication for above mentioned reasons!

- I will be remembered for posterity and my footprints will be etched in sands of time. Publications may not make me rich, bit they will make me famous nevertheless!

The alternative to publication

In my case despite having made what I considered earth shattering discoveries, I did not have any of the eight reasons mentioned above, compelling me to publish in peer reviewed journals, and this was a problem that needed to be solved, because if I did not publish, I would certainly not perish, but my ideas would die with me and nobody would be benefited with them in posterity!

I thus took to social media, and began disseminating my special tricks, tips and techniques, and soon had a very large number of young surgeons eagerly trying my methods and achieving a considerable amount of success, and their enthusiastic messages validated my ideas and theories! Whatsapp groups, Facebook [15], YouTube [16], Blogs, Quora [17], and Instagram [18], were the platforms on which I attempted to disseminate my knowledge! 
The outcome

Today over ten topics to which I had contributed or invented, are being studied as thesis topics in nineteen universities across the world. Already many publications have started appearing in journals, supporting my methods or even describing them for the first time, with due credits given to me! The topics that are being studied by resident trainees as a part of their post graduation are

- Prakash method of reducing shoulder dislocations [19]

- $\quad$ Extension casting of humerus fracture [20]

- Distal Sodium Channel Blocks in Sciatica and back pains [21].

- Diwaker method of gravity reduction of supracondylar fractures of humerus! [22]

- $\quad$ DSCB and intermittent bracing for clavicular or humeral fractures [23]

- $\quad$ The Tangari Prakash Trauma System [24]

- Three wire Ilizarov technique for distal radial fractures [25]

- $\quad$ DSCB as the definitive management in MRI proven rotator cuff tears [26]

- $\quad$ PFO for medial compartment arthritis of the knee [27]

- Extension casting in adult forearm fractures [28].

\section{Conclusions}

Today many of the ideas which I originally posted on Facebook, YouTube or whatsapp groups, have been evaluated, analysed, studied and published in indexed journals by colleagues who found the methods effective in their patients!

Not writing up papers for publication in indexed journals has never affected me or my career, and I never had to falsify results or cook up statistics to ensure that my article is publication worthy!

\section{Bibliography}

1. Rawat Seema and Sanjay Meena. "Publish or perish: Where are we heading?". Journal of Research in Medical Sciences : The Official Journal of Isfahan University of Medical Sciences 19.2 (2014): 87-89.
2. Coolidge HJ. United States: Books for Libraries. Archibald Cary Coolidge: Life and Letters (1932): 308.

3. https://www.youtube.com/channel/UCf4aJ-Kh2YjN9QZl499gn5Q/videos

4. Bauerlein M., et al. "We must stop the avalanche of low- quality research". The Chronicle of Higher Education (2010).

5. http://www.editorialmanager.com/jbjs

6. Björk B., et al. "Scientific journal publishing: yearly volume and open access availability". Information Research (2009).

7. Abbott A., et al. "Metrics: Do metrics matter?" Nature 465 (2010): 860 .

8. Beaufils $\mathrm{P}$ and Karlsson J. "Legitimate division of large datasets, salami slicing and dual publication. Where does a fraud begin?" Orthopaedics and Traumatology: Surgery and Research 99 (2013): 121-122.

9. Masic I. "Ethical aspects and dilemmas of preparing, writing and publishing of the scientific papers in the biomedical journals". Acta Informatica Medica 20 (2012): 141-148.

10. Reuters T. Journal self-citation in the journal citation reports (2011).

11. Barton CJ and Merolli MA. "It is time to replace publish or perish with get visible or vanish: opportunities where digital and social media can reshape knowledge translation". British Journal of Sports Medicine 53 (2019): 594-598.

12. https://www.enago.com/academy/publish-or-perish-consequences/

13. https://en.wikipedia.org/wiki/Publish_or_perish

14. https://www.enago.com/academy/salami- slicing-in-research-publications/

15. https://www.facebook.com/lakshmanan.prakash 
16. https://www.youtube.com/channel/UCf4aJ-Kh2YjN9QZl499gn5Q/videos

17. https://www.quora.com/Why-are-90-of-the-hip-replacements-in-India-Hemiarthroplasty-and-only-10-are-total-arthroplasty-while-it-is-vice-versa-in-the-USA/answer/Lakasmanan-Prakash

18. https://www.instagram.com/drlprakash/

19. https://www.youtube.com/watch?v=ZGGnB0gz2qY

20. https://www.youtube.com/watch?v=uSdkkQXvAE0

21. https://www.youtube.com/watch?v=MRw8ns80xV8

22. https://www.youtube.com/watch?v=pifbrTsPnj0

23. https://www.youtube.com/watch?v=jOzFfKIxLyA

24. https://www.youtube.com/watch?v=BzRKnBEiMig

25. https://www.youtube.com/watch?v=I1fnj9Wsagg

26. https://www.youtube.com/watch?v=bkpb3Ydo5Zg

27. https://www.youtube.com/watch?v=Ye2wcrDFZtA

28. https://www.youtube.com/watch?v=S4ToxNoPnLAa

\section{Assets from publication with us}

- Prompt Acknowledgement after receiving the article

- Thorough Double blinded peer review

- Rapid Publication

- Issue of Publication Certificate

- High visibility of your Published work

Website: https://www.actascientific.com/

Submit Article: https://www.actascientific.com/submission.php

Email us: editor@actascientific.com

Contact us: +919182824667

Citation: L Prakash. "Social Media as an Alternative to Peer Reviewed Journal Publications". Acta Scientific Orthopaedics 4.2 (2021): 27-30. 